\title{
Effects of Race, Ethnicity, and Gender on Surgical Mortality in Hypoplastic Left Heart Syndrome
}

\author{
Peter N. Dean, \\ Division of Cardiology, Children's National Medical Center, 111 Michigan Avenue, Washington, \\ DC 20010-2970, USA \\ Kimberly E. McHugh, \\ Division of Cardiology, Department of Pediatrics, Medical University of South Carolina, \\ Charleston, SC, USA \\ Mark R. Conaway, \\ Division of Translational Research and Applied Statistics, Department of Public Health Sciences, \\ University of Virginia Health System, Charlottesville, VA, USA \\ Diane G. Hillman, and \\ Department of Public Health Sciences, University of Virginia Health System, Charlottesville, VA, \\ USA
}

\author{
Howard P. Gutgesell \\ Division of Cardiology, Department of Pediatrics, University of Virginia Health System, \\ Charlottesville, VA, USA \\ Peter N. Dean: pdean@childrensnational.org
}

\section{Abstract}

Information is limited regarding the effect of race, ethnicity, and gender on the outcomes of the three palliative procedures for hypoplastic left heart syndrome (HLHS). This study examined the effects of race, ethnicity, gender, type of admission, and surgical volume on in-hospital mortality associated with palliative procedures for HLHS between 1998 and 2007 using data from the University HealthSystem Consortium. According to the data, 1,949 patients underwent stage 1 palliation (S1P) with a mortality rate of $29 \%, 1,279$ patients underwent stage 2 palliations (S2P) with a mortality rate of $5.4 \%$, and 1,084 patients underwent stage 3 palliation (S3P) with a mortality rate of $4.1 \%$. The risk factors for increased mortality with S1P were black and "other" race, smaller surgical volume, and early surgical era. The only risk factors for increased mortality with S2P were black race (11\% mortality; odds ratio [OR], 3.19; $95 \%$ confidence interval [CI] 1.69-6.02) and Hispanic ethnicity (11\% mortality; OR 3.30; $95 \%$ CI 1.64-6.64). For S2P, no racial differences were seen in the top five surgical volume institutions, but racial differences were seen in the non-top-five surgical volume institutions. Mortality with S1P was significantly higher

\footnotetext{
(C) Springer Science+Business Media New York 2013

Correspondence to: Peter N. Dean, pdean@childrensnational . org.

Presented at the American College of Cardiology's Sixty-Second Scientific Session, San Francisco, CA, 9 March 2013.

Conflicts of interest The authors have no conflicts of interest to disclose.
} 
for patients discharged after birth ( 37 vs $24 \% ; p=0.004$ ), and blacks were more likely to be discharged after birth (12 vs $5 \%$ for all other races; $p<0.001$ ). No racial differences with S3P were observed. The risk factors for increased mortality at S1P were black and "other" race, smaller surgical volume, and early surgical era. The risk factors for increased in-hospital mortality with S2P were black race and His-panic ethnicity.

\section{Keywords}

Congenital heart disease; Congenital heart surgery; Hypoplastic left heart syndrome; Racial disparities

\section{Background}

Although the overall mortality rate for patients with congenital heart disease (CHD) has decreased significantly over the last several decades [6, 22], mortality among black and Hispanic patients with CHD has not decreased as dramatically as among white patients [6, 22]. Several national database studies have shown that black and Hispanic patients with CHD have a higher surgical mortality rate than white patients $[4,8,15,23,36,38]$, but these studies have not analyzed specific diagnoses or individual procedures.

Outcomes specifically for children with hypoplastic left heart syndrome (HLHS) also have improved but remain unacceptably high [14, 16-18, 31, 32]. Black patients with singleventricle lesions and Hispanic patients with HLHS have a higher early childhood mortality than white patients $[18,19,35]$. The reasons for the increased mortality rate for black and Hispanic patients are unclear because the studies did not distinguish between surgical, inhospital, and interstage mortality.

In the current study, we used data from a large, multi-institutional database to investigate the effect of race, ethnicity, and gender on the in-hospital mortality for the three palliative procedures commonly used in the management of HLHS.

\section{Materials and Methods}

Data were obtained from the Clinical Database/Resource Manager maintained by the University HealthSystem Consortium (UHC). The UHC is an alliance of 116 academic medical centers and 276 affiliated hospitals that share demographic, diagnostic, procedural, and financial data on all discharges.

Encoded hospital identifiers were provided for individual institutions. The study was approved by the University of Virginia Institutional Review Board.

The database was queried for data on all patients discharged between 1998 and 2007 with the diagnosis of HLHS based on International Classification of Diseases, Ninth Revision, Clinical Modification (ICD-9) code 746.7. Procedures during each hospitalization were determined by using the listed procedure codes as previously described [32]. 
We collected information regarding race, ethnicity, gender, age at surgery, admission source, and discharge status for the three procedures used in palliation of HLHS between 1998 and 2007. The early surgical era was defined as 1998-2002 and the late surgical era as 2003-2007. For each of the three surgical procedures, the five institutions that performed the most procedures performed approximately half of the total and are subsequently referred to as "large-volume" institutions. The remaining institutions are referred to as "small-volume" institutions. The large-volume institutions each performed more than 124 stage 1 palliative (S1P) procedures (Norwood procedure with either Blalock-Taussig shunt or Sano modification), more than 76 stage 2 palliative (S2P) procedures (Glenn procedure), and more than 54 stage 3 palliative (S3P) procedures (Fontan procedure) during the ten year study period.

The patients were classified as black, Hispanic, white, or "other" (including Asian and Native American patients) by the admitting hospital. Patients for whom race was listed as "unknown" were included in the overall mortality analysis but not in the racial comparisons. Some institutional protocols do not allow date of birth or race information to be sent to the UHC, so the numbers for analyses involving race and age are fewer than those for the total cohort.

The admission source was used to determine whether a patient had been discharged to home before diagnosis. Because neonates with a known diagnosis of HLHS are rarely, if ever, discharged home before an S1P procedure, it was assumed that all patients admitted under the category, "ED referral," "clinic referral," "HMO referral," "extramural birth," or "physician/MD referral" had been discharged home after birth without a diagnosis of HLHS. It was assumed that the diagnosis for inborn and transferred neonates was determined either prenatally or during the immediate newborn period.

Mortality rates were determined on the basis of survival to discharge. Data on mortality after discharge are not included in the data set.

For each disease stage, the effects of race, gender, admission status, institutional surgical volume, and surgical era on in-hospital mortality were compared by Chi square analysis (SAS, version 9.2; SAS Institute Inc., Cary, NC, USA). Logistic regression was used to assess the simultaneous effect of these factors and their two-way interactions on mortality risk. Additionally, for S1P, the effect of prematurity was assessed by Chi square analysis, and for S2P and S3P procedures, the age at the time of surgery for each of the racial/ethnic groups was compared using a Kruskal-Wallis test.

\section{Results}

Between 1998 and 2007, 48 UHC institutions performed 1,949 S1P procedures, 47 institutions performed 1,279 S2P procedures, and 46 institutions performed 1,084 S3P procedures (Table 1). Racial information was missing for 220 patients who underwent S1P, 55 who underwent S2P, and 52 who underwent S3P. 


\section{Unadjusted Outcomes (Table 1)}

For S1P, the overall in-hospital mortality rate was $28.6 \%$. The mortality rate was higher among females (31.6 vs $26.7 \% ; p=0.045)$. It was significantly lower at large-volume institutions than at small-volume institutions (23.6 vs $34.3 \% ; p<0.0001)$. Racial differences were seen at both large- and small-volume institutions. The mortality rate was significantly higher for patients admitted from home to the institution that performed the S1P (36.9\%) than for those born at or transferred to the institution that performed the S1P (27.7\%; $p=0.045)$. Black patients were more likely to have been admitted from home than nonblack patients ( 12 vs $5 \% ; p<0.001)$. The incidence of prematurity did not differ significantly between races $(p=0.62)$ and ranged between 8 and $10 \%$ for each race.

The in-hospital mortality rate for patients undergoing S2P procedures was $5.4 \%$. The overall mortality rate at the large-volume institutions was similar to that at the small-volume institutions (5.5 and $5.3 \% ; p=0.84$ ), but blacks and Hispanics had increased mortality (13.5 and $13.2 \%$, respectively; $p<0.001)$ at the small-volume centers. Age at the S2P procedure was available for 812 patients and did not differ significantly across races $(p=0.25)$.

The in-hospital mortality rate for the patients undergoing S3P procedures was $4.1 \%$. Gender, race, ethnicity, institutional surgical volume, and surgical era did not influence mortality. Age at S3P was available for 818 patients and did not differ significantly across races $(p=0.31)$.

\section{Adjusted Outcomes (Table 2)}

The results for logistic regression analysis are shown in Table 2. For stage 1 palliation, black and "other" race, smaller surgical volume, and early surgical era were significant risk factors for in-hospital mortality. Female gender trended toward but did not reach statistical significance and admission category was not significant.

For stage 2 palliation, black race and Hispanic ethnicity were significant risk factors for inhospital mortality. Gender, institutional surgical volume, and surgical era were not significant.

\section{Discussion}

Using a large, national hospital database, we identified several risk factors for increased mortality for the three palliative procedures commonly used to treat patients with HLHS. For S1P, the risk factors were black and "other" race, smaller surgical volume, and early surgical era. For S2P, the risk factors were black race and Hispanic ethnicity. For S1P, female gender and discharge before diagnosis were significant in the unadjusted analysis but not significant when adjustment was performed for other factors. No risk factors were identified for S3P palliation. The most novel finding in our study was the increased risk of in-hospital mortality for black and "other" race patients at S1P and for black and Hispanic patients at the time of S2P.

Using large national inpatient databases, other studies $[4,8,15,23,36]$ have demonstrated increased mortality for black and Hispanic patients undergoing surgery for CHD, but these 
studies did not describe mortality for specific diagnoses or procedures. Three studies using the Texas Birth Defect Registry focused on single-ventricle-physiology patients and demonstrated racial differences in early childhood survival $[18,19,35]$. Our study indicates that these discrepancies in early childhood mortality are partially due to increased inhospital mortality at S1P for black and "other" race patients and increased in-hospital mortality at S2P for black and Hispanic patients. The increased mortality does not appear to be due to racial groups undergoing procedures at smaller-volume institutions because approximately half of the black and "other" race patients had their procedures performed at a large-volume institution, and approximately half of the black and Hispanic patients had their S2P procedures at a large-volume institution.

The reason for the increased mortality rate for black and Hispanic patients at S2P is unclear. Previous studies have shown that lower weight-for-age $z$-scores increase the risk of complications after S2P [1, 33]. More recently, Anderson et al. [2] demonstrated that nonCaucasian races have lower weight-for-age $z$-scores.

Our database did not contain data on weight or nutritional status, so we were unable to determine whether these factors contributed to the increased mortality among blacks and Hispanics. The racial differences seen at both large-and small-volume institutions at S1P and the lack of racial differences at the five institutions performing the largest number of S2P procedures argues against biologic factors as a cause for the racial differences in mortality. We speculate that more resources and more robust interstage monitoring programs at largevolume institutions may help to eliminate the racial differences at S2P.

In our study, age at $\mathrm{S} 2 \mathrm{P}$ and $\mathrm{S} 3 \mathrm{P}$ did not differ significantly between the races. Several studies have found that blacks undergo S2P at an older age than whites [11, 34], but our findings coincide with those of Ingaramo et al. [26], who also found no significant racial difference in age at S2P and S3P in a large national database.

In our cohort, the patients admitted from home at the time of their S1P operation had a significantly higher unadjusted mortality rate than those born at or transferred to the institution that performed the S1P (36.9 vs $27.7 \%$ ). Although logistic regression did not find this to be significant, we believe it may be due to the high percentage of black patients discharged home before diagnosis ( $12 \mathrm{vs} 5 \%$ for all other races). This finding adds to the growing evidence that screening for CHD in the prenatal period [42] or in the newborn nursery is important [7, 20, 29, 30,40], especially for infants whose skin pigmentation may prevent adequate visual assessment of cyanosis [29].

Similar to previous studies, we found increased risk of death for smaller surgical volume and earlier surgical era $[5,10,24,25]$. Although black patients have an overall higher incidence of prematurity [12] and although other studies have shown that prematurity is an independent risk factor for mortality [3, 21, 37, 39, 41], in our patients, the incidence of prematurity was similar across races and did not contribute to racial disparities.

Although some studies have shown increased mortality for female infants undergoing cardiac procedures $[4,9,27,38]$, we did not find a gender discrepancy in adjusted analysis 
for any of the three palliative procedures. Other studies looking specifically at risk factors associated with S1P for HLHS also have not found a gender difference [25, 28, 37, 39].

For S1P, the finding that "other" races had increased inhospital mortality is difficult to interpret. Whereas a small number of these patients were Asian or Native American/Eskimo, the majority simply had "other" listed as their race. We do not know whether the patient's family identified itself as an unlisted race or had a multiracial lineage, or whether the person entering the information in the database was uncertain about the race of the patient. This limitation is true of virtually all the racial studies involving CHD $[4,8,15,23,36]$ and is difficult to avoid in a multiracial county such as the United States. Our data were similar to those of Oster et al. [36] and Dibardino et al. [15], each of whom found increased mortality for "other" races after congenital heart procedures.

The limitations of our study were those related to the use of an administrative discharge database, especially one based on the ICD-9 procedure coding system, which has no specific code for S1P (Norwood procedure). We attempted to circumvent this by using both the ICD-9 diagnostic and procedural codes to identify patients, as previously described [13, 32]. We did not have clinical data such as weight, nutritional status, oxygen saturation, metabolic status, or the presence of a prenatal diagnosis, factors that may have explained some of the differences in mortality. We also did not have information regarding socioeconomic status, data that may have served as a surrogate for access to care.

We made several assumptions regarding admission category for the S1P hospitalization. Admission category (inborn vs outborn) is admittedly a crude way to determine clinical status, although it may have validity for the neonate with HLHS, whose clinical deterioration may occur very rapidly. We also assumed that patients transferred to the S1P institution were born at the referring institution and had the diagnosis of HLHS there. Because some of them may have been discharged before admittance to the referring institution, we may have underestimated the number of patients admitted from home.

\section{Conclusions}

In a large, nationwide database, we found that the independent risk factors for increased inhospital mortality at S1P for HLHS were black and "other" race, lower surgical volume, and earlier surgical era. The risk factors for increased mortality at S2P were black race and Hispanic ethnicity. The fact that the five institutions performing the largest number of procedures did not differ in mortality at $\mathrm{S} 2 \mathrm{P}$ suggests that the racial differences are not innate and can be minimized by the implementation of routine pulse oximetry screening programs in the newborn period, increased interstage monitoring, and better pre-S2P nutrition of patients with HLHS.

\section{Abbreviations}

$\begin{array}{ll}\text { CHD } & \text { Congenital heart disease } \\ \text { HLHS } & \text { Hypoplastic left heart syndrome }\end{array}$


S1P Stage 1 palliation (Norwood procedure)

S2P Stage 2 palliation (Glenn or Hemi-Fontan procedure)

S3P Stage 3 palliation (Fontan procedure)

UHC University HealthSystem Consortium

\section{References}

1. Anderson JB, Beekman RH III, Border WL, Kalkwarf HJ, Khoury PR, Uzark K, Eghtesady P, Marino BS. Lower weight-for-age $z$-score adversely affects hospital length of stay after the bidirectional Glenn procedure in 100 infants with a single ventricle. J Thorac Cardiovasc Surg. 2009; 138:397-404. discussion e391. [PubMed: 19619784]

2. Anderson JB, Beekman RH III, Eghtesady P, Kalkwarf HJ, Uzark K, Kehl JE, Marino BS. Predictors of poor weight gain in infants with a single ventricle. J Pediatr. 2010; 157:407-413. 413e401. [PubMed: 20472248]

3. Artrip JH, Campbell DN, Ivy DD, Almodovar MC, Chan KC, Mitchell MB, Clarke DR, LacourGayet F. Birth weight and complexity are significant factors for the management of hypoplastic left heart syndrome. Ann Thorac Surg. 2006; 82:1252-1257. discussion 1258-1259. [PubMed: 16996917]

4. Benavidez OJ, Gauvreau K, Jenkins KJ. Racial and ethnic disparities in mortality following congenital heart surgery. Pediatr Cardiol. 2006; 27:321-328. [PubMed: 16565899]

5. Berry JG, Cowley CG, Hoff CJ, Srivastava R. In-hospital mortality for children with hypoplastic left heart syndrome after stage I surgical palliation: teaching versus nonteaching hospitals. Pediatrics. 2006; 117:1307-1313. [PubMed: 16585328]

6. Boneva RS, Botto LD, Moore CA, Yang Q, Correa A, Erickson JD. Mortality associated with congenital heart defects in the United States: trends and racial disparities, 1979-1997. Circulation. 2001; 103:2376-2381. [PubMed: 11352887]

7. Brown KL, Ridout DA, Hoskote A, Verhulst L, Ricci M, Bull C. Delayed diagnosis of congenital heart disease worsens preoperative condition and outcome of surgery in neonates. Heart. 2006; 92:1298-1302. [PubMed: 16449514]

8. Chan T, Pinto N, Bratton S. Racial and insurance disparities in hospital mortality for children undergoing congenital heart surgery. Pediatr Cardiol. 2012; 33(7):1026-1039. [PubMed: 22349675]

9. Chang RK, Chen AY, Klitzner TS. Female sex as a risk factor for in-hospital mortality among children undergoing cardiac surgery. Circulation. 2002; 106:1514-1522. [PubMed: 12234958]

10. Checchia PA, McCollegan J, Daher N, Kolovos N, Levy F, Markovitz B. The effect of surgical case volume on outcome after the Norwood procedure. J Thorac Cardiovasc Surg. 2005; 129:754759. [PubMed: 15821640]

11. Cnota JF, Allen KR, Colan S, Covitz W, Graham EM, Hehir DA, Levine JC, Margossian R, McCrindle BW, Minich LL, Natarajan S, Richmond ME, Hsu DT. Pediatric Heart Network I. Superior cavopulmonary anastomosis timing and outcomes in infants with single ventricle. J Thorac Cardiovasc Surg. 2012; 145(5):1288-1296. [PubMed: 22939855]

12. Culhane JF, Goldenberg RL. Racial disparities in preterm birth. Semin Perinatol. 2011; 35:234239. [PubMed: 21798403]

13. Dean PN, Hillman DG, McHugh KE, Gutgesell HP. Inpatient costs and charges for surgical treatment of hypoplastic left heart syndrome. Pediatrics. 2011; 128:e1181-e1186. [PubMed: 21987703]

14. Delmo Walter EM, Hubler M, Alexi-Meskishvili V, Miera O, Weng Y, Loforte A, Berger F, Hetzer R. Staged surgical palliation in hypoplastic left heart syndrome and its variants. J Card Surg. 2009; 24:383-391. [PubMed: 19040407]

15. Dibardino DJ, Pasquali SK, Hirsch JC, Benjamin DK, Kleeman KC, Salazar JD, Jacobs ML, Mayer JE, Jacobs JP. Effect of sex and race on outcome in patients undergoing congenital heart 
surgery: an analysis of the society of thoracic surgeons congenital heart surgery database. Ann Thorac Surg. 2012; 94:2054-2060. [PubMed: 22884593]

16. d'Udekem Y, Xu MY, Galati JC, Lu S, Iyengar AJ, Konstantinov IE, Wheaton GR, Ramsay JM, Grigg LE, Millar J, Cheung MM, Brizard CP. Predictors of survival after single-ventricle palliation: the impact of right ventricular dominance. J Am Coll Cardiol. 2012; 59:1178-1185. [PubMed: 22440217]

17. Feinstein JA, Benson DW, Dubin AM, Cohen MS, Maxey DM, Mahle WT, Pahl E, Villafane J, Bhatt AB, Peng LF, Johnson BA, Marsden AL, Daniels CJ, Rudd NA, Caldarone CA, Mussatto KA, Morales DL, Ivy DD, Gaynor JW, Tweddell JS, Deal BJ, Furck AK, Rosenthal GL, Ohye RG, Ghanayem NS, Cheatham JP, Tworetzky W, Martin GR. Hypoplastic left heart syndrome: current considerations and expectations. J Am Coll Cardiol. 2012; 59:S1-S42. [PubMed: 22192720]

18. Fixler DE, Nembhard WN, Salemi JL, Ethen MK, Canfield MA. Mortality in first 5 years in infants with functional single ventricle born in Texas, 1996-2003. Circulation. 2010; 121:644650. [PubMed: 20100974]

19. Fixler DE, Nembhard WN, Xu P, Ethen MK, Canfield MA. Effect of acculturation and distance from cardiac center on congenital heart disease mortality. Pediatrics. 2012; 129:1118-1124. [PubMed: 22566422]

20. Frank LH, Bradshaw E, Beekman R, Mahle WT, Martin GR. Critical congenital heart disease screening using pulse oximetry. J Pediatr. 2013; 162(3):445-453. [PubMed: 23266220]

21. Gaynor JW, Mahle WT, Cohen MI, Ittenbach RF, DeCampli WM, Steven JM, Nicolson SC, Spray TL. Risk factors for mortality after the Norwood procedure. Eur J Cardiothorac Surg. 2002; 22:82-89. [PubMed: 12103378]

22. Gilboa SM, Salemi JL, Nembhard WN, Fixler DE, Correa A. Mortality resulting from congenital heart disease among children and adults in the United States, 1999-2006. Circulation. 2010; 122:2254-2263. [PubMed: 21098447]

23. Gonzalez PC, Gauvreau K, Demone JA, Piercey GE, Jenkins KJ. Regional racial and ethnic differences in mortality for congenital heart surgery in children may reflect unequal access to care. Pediatr Cardiol. 2003; 24:103-108. [PubMed: 12360393]

24. Gordon BM, Rodriguez S, Lee M, Chang RK. Decreasing number of deaths of infants with hypoplastic left heart syndrome. J Pediatr. 2008; 153:354-358. [PubMed: 18534240]

25. Hirsch JC, Gurney JG, Donohue JE, Gebremariam A, Bove EL, Ohye RG. Hospital mortality for Norwood and arterial switch operations as a function of institutional volume. Pediatr Cardiol. 2008; 29:713-717. [PubMed: 18080151]

26. Ingaramo OA, Khemani RG, Markovitz BP, Epstein D. Effect of race on the timing of the Glenn and Fontan procedures for single-ventricle congenital heart disease. Pediatr Crit Care Med. 2012; 13:174-177. [PubMed: 21666532]

27. Klitzner TS, Lee M, Rodriguez S, Chang RK. Sex-related disparity in surgical mortality among pediatric patients. Congenit Heart Dis. 2006; 1:77-88. [PubMed: 18377550]

28. Mahle WT, Spray TL, Wernovsky G, Gaynor JW, Clark BJ III. Survival after reconstructive surgery for hypoplastic left heart syndrome: a 15-year experience from a single institution. Circulation. 2000; 102:III136-III141. [PubMed: 11082376]

29. Mahle WT, Newburger JW, Matherne GP, Smith FC, Hoke TR, Koppel R, Gidding SS, Beekman RH III, Grosse SD. American Heart Association Congenital Heart Defects Committee of the Council on Cardiovascular Disease in the Young CoCN, Interdisciplinary Council on Quality of C, Outcomes R, American Academy of Pediatrics Section on C, Cardiac S, Committee on F, Newborn. Role of pulse oximetry in examining newborns for congenital heart disease: a scientific statement from the AHA and AAP. Pediatrics. 2009; 124:823-836. [PubMed: 19581259]

30. Mahle WT, Martin GR, Beekman RH III, Morrow WR. Section on Cardiology and Cardiac Surgery Executive Committee. Endorsement of health and human services recommendation for pulse oximetry screening for critical congenital heart disease. Pediatrics. 2012; 129:190-192. [PubMed: 22201143] 
31. McGuirk SP, Griselli M, Stumper OF, Rumball EM, Miller P, Dhillon R, de Giovanni JV, Wright JG, Barron DJ, Brawn WJ. Staged surgical management of hypoplastic left heart syndrome: a single-institution 12-year experience. Heart. 2006; 92:364-370. [PubMed: 15939721]

32. McHugh KE, Hillman DG, Gurka MJ, Gutgesell HP. Three-stage palliation of hypoplastic left heart syndrome in the University healthsystem consortium. Congenit Heart Dis. 2010; 5:8-15. [PubMed: 20136852]

33. Menon SC, McCandless RT, Mack GK, Lambert LM, McFadden M, Williams RV, Minich LL. Clinical outcomes and resource use for infants with hypoplastic left heart syndrome during bidirectional Glenn: summary from the joint council for congenital heart disease national pediatric cardiology quality improvement collaborative registry. Pediatr Cardiol. 2012; 34(1):143-148. [PubMed: 22673966]

34. Milazzo AS Jr, Sanders SP, Armstrong BE, Li JS. Racial and geographic disparities in timing of bidirectional Glenn and Fontan stages of single-ventricle palliation. J Natl Med Assoc. 2002; 94:873-878. [PubMed: 12408691]

35. Nembhard WN, Salemi JL, Ethen MK, Fixler DE, Dimaggio A, Canfield MA. Racial/ethnic disparities in risk of early childhood mortality among children with congenital heart defects. Pediatrics. 2011; 127:e1128-e1138. [PubMed: 21502234]

36. Oster ME, Strickland MJ, Mahle WT. Racial and ethnic disparities in postoperative mortality following congenital heart surgery. J Pediatr. 2011; 159:222-226. [PubMed: 21414631]

37. Sano S, Huang SC, Kasahara S, Yoshizumi K, Kotani Y, Ishino K. Risk factors for mortality after the Norwood procedure using right ventricle-to-pulmonary artery shunt. Ann Thorac Surg. 2009; 87:178-185. discussion 185-176. [PubMed: 19101293]

38. Seifert HA, Howard DL, Silber JH, Jobes DR. Female gender increases the risk of death during hospitalization for pediatric cardiac surgery. J Thorac Cardiovasc Surg. 2007; 133:668-675. [PubMed: 17320563]

39. Stasik CN, Gelehrter S, Goldberg CS, Bove EL, Devaney EJ, Ohye RG. Current outcomes and risk factors for the Norwood procedure. J Thorac Cardiovasc Surg. 2006; 131:412-417. [PubMed: 16434272]

40. Thangaratinam S, Brown K, Zamora J, Khan KS, Ewer AK. Pulse oximetry screening for critical congenital heart defects in asymptomatic newborn babies: a systematic review and meta-analysis. Lancet. 2012; 379:2459-2464. [PubMed: 22554860]

41. Tweddell JS, Sleeper LA, Ohye RG, Williams IA, Mahony L, Pizarro C, Pemberton VL, Frommelt PC, Bradley SM, Cnota JF, Hirsch J, Kirshbom PM, Li JS, Pike N, Puchalski M, Ravishankar C, Jacobs JP, Laussen PC, McCrindle BW. Pediatric Heart Network I. Intermediate-term mortality and cardiac transplantation in infants with single-ventricle lesions: risk factors and their interaction with shunt type. J Thorac Cardiovasc Surg. 2012; 144:152-159. [PubMed: 22341427]

42. Tworetzky W, McElhinney DB, Reddy VM, Brook MM, Hanley FL, Silverman NH. Improved surgical outcome after fetal diagnosis of hypoplastic left heart syndrome. Circulation. 2001; 103:1269-1273. [PubMed: 11238272] 


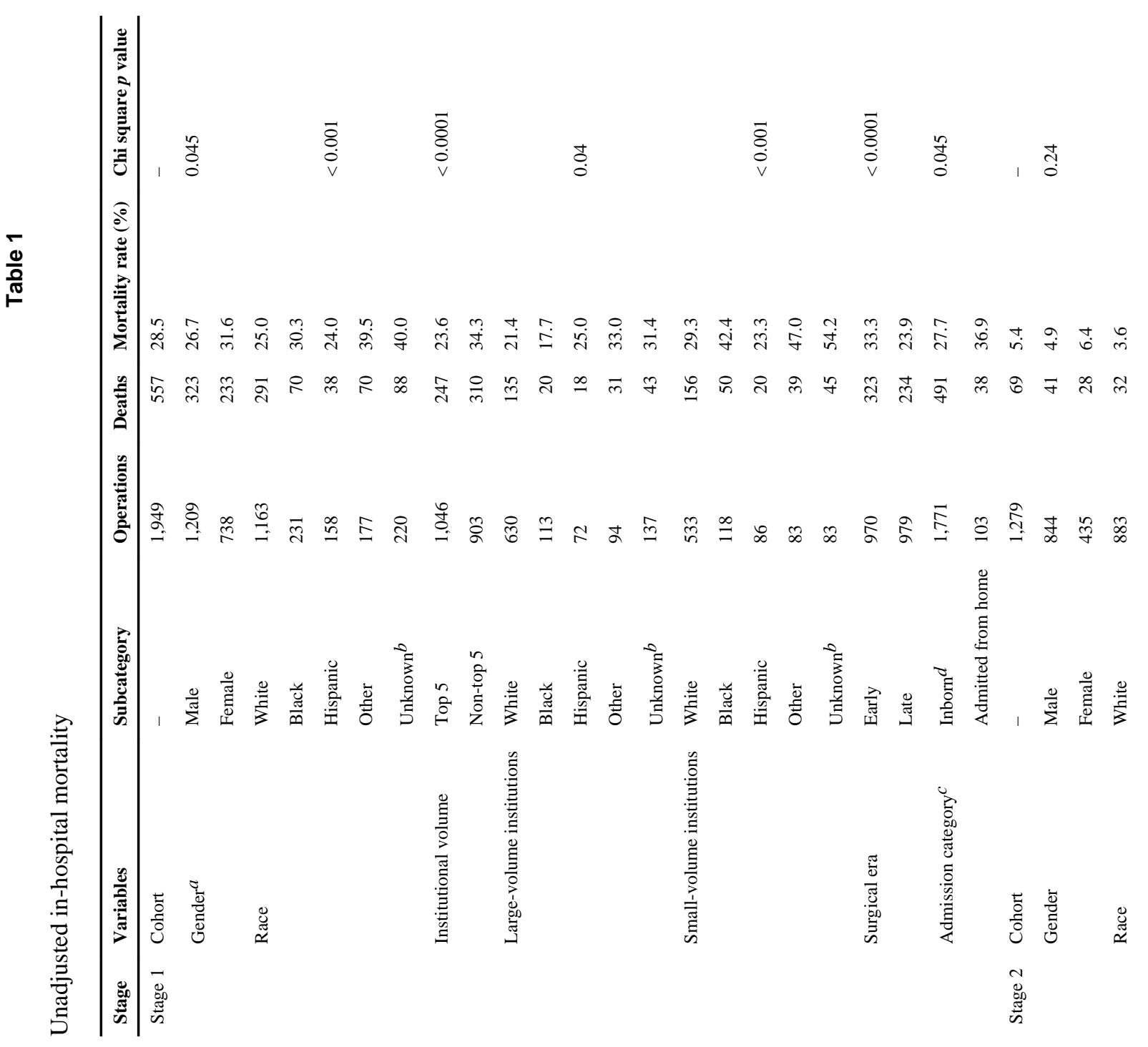

Pediatr Cardiol. Author manuscript; available in PMC 2014 May 16. 


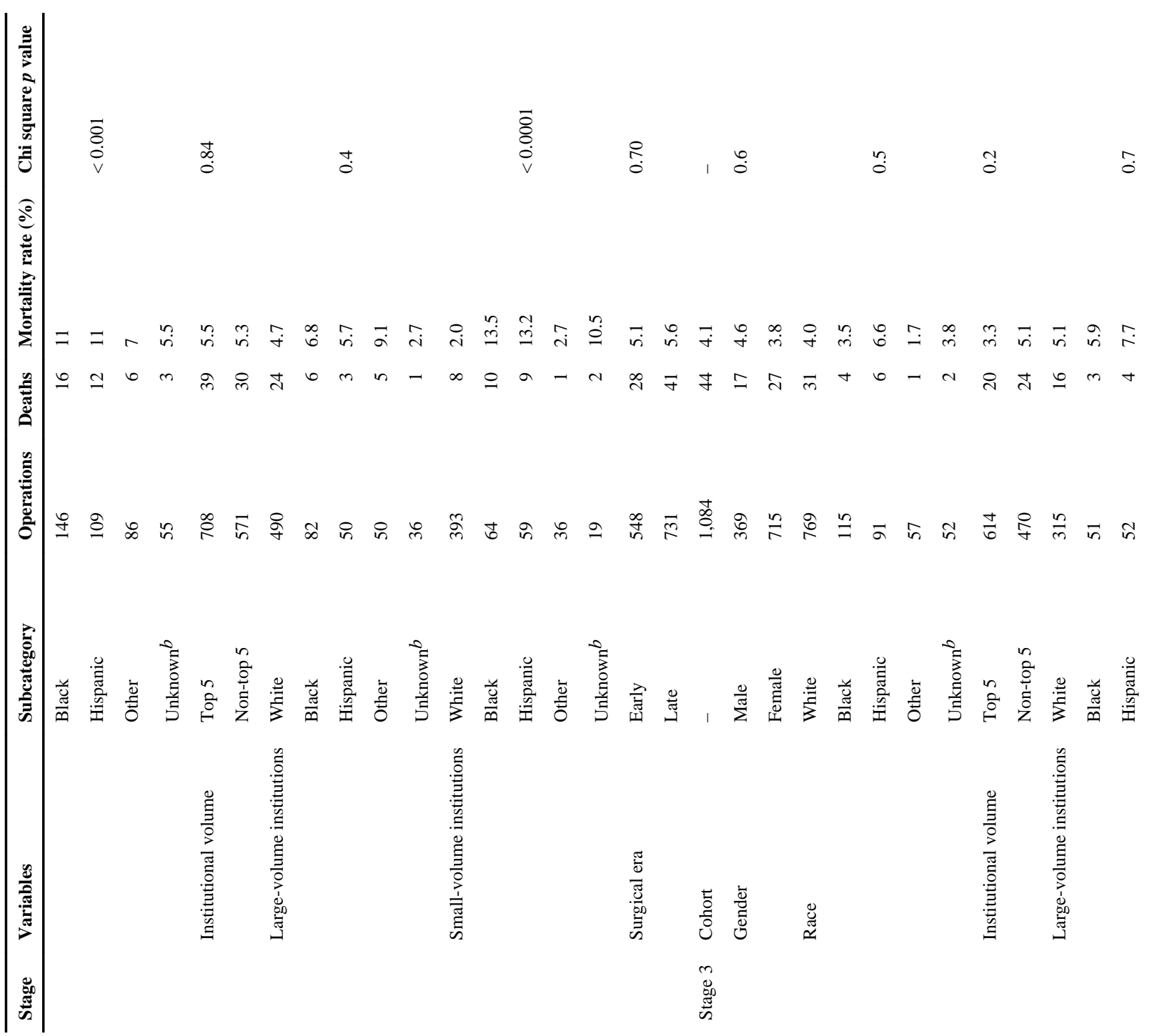




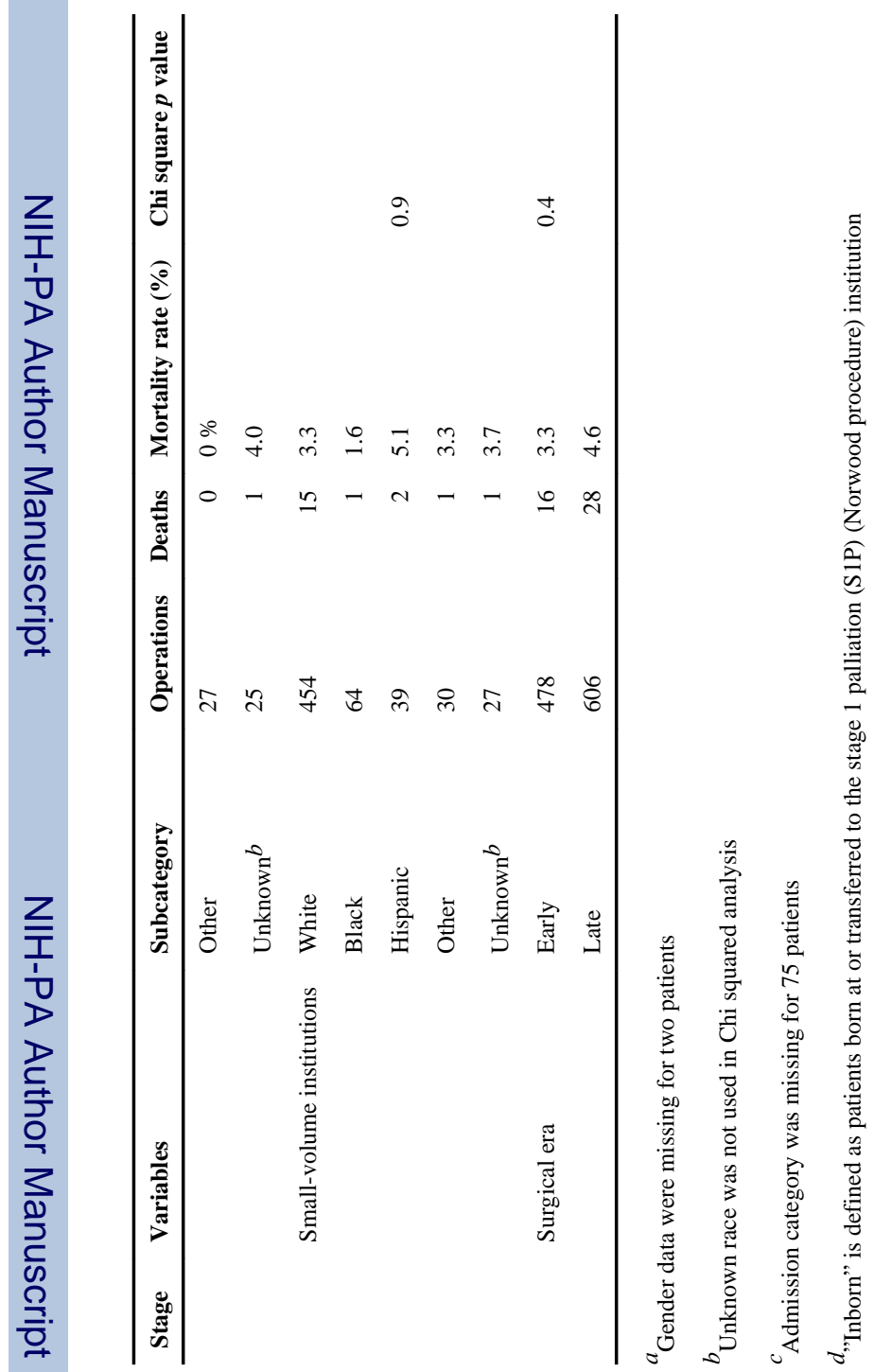

Pediatr Cardiol. Author manuscript; available in PMC 2014 May 16. 
